\title{
Creationism and Cardinality
}

Daniel Nolan and Alexander Sandgren. To appear in Analysis.

Creationism about fictional entities is the doctrine that fictional entities come into existence when the fictions about them are composed: it may be contrasted both with a more platonist view according to which all potential fictional entities have always existed, and eliminativist views according to which there are no merely fictional entities. Creationism is alleged to have a number of advantages over platonism. Three important ones are parsimony, since we do not need to postulate quite so many kinds of fictional entities; a more naturalistic flavour, since the created entities are plausibly thought to be dependent on concrete goings-on; and a better fit, at least in some respects, with ordinary talk, since we talk as if e.g. Conan Doyle is the creator of Sherlock Holmes, as well as the Sherlock Holmes stories.

Creationism, however, suffers from paradox, and straightforward formulations of creationism lead to contradiction. Specifically, we will argue, straightforward creationist theories suffer from cardinality paradoxes, providing inconsistent answers to the question of how many fictional objects there are. This is not much of an advantage for platonism about fictional entities, since naive platonistic theories of abstract objects often face cardinality paradoxes, and naive platonistic theories of fictional entities are no exception. But one might have thought creationism, in avoiding the abundance of platonism, might avoid the over-generous principles that lead to paradox. Unfortunately, not so. After explaining how straightforward creationism is refuted, we will briefly discuss the prospects for avoiding this paradox 
in a principled manner. Our main purpose in this paper is to point to the problem, since creationists to date may well not have avoided it. Among the creationist theories of fictional objects that do not have any explicit resources to avoid this problem are those of Salmon (1998, esp 293-296), Thomasson (1996, 300-307, 1999, 5-14), and Kripke (2013, 71-78).

\section{Creationism}

According to the creationist, fictional entities exist in virtue of being featured in fictions. Holmes exists in virtue of appearing in the Sherlock Holmes stories, and was brought into existence when the relevant fiction was composed. Fictional objects have properties according to the fiction. In the fiction Holmes lives in London. Holmes does not really live in London, he only fictionally lives in London. He is not clever, he is only fictionally clever and so on. They also have non-fictional properties. Holmes, the fictional entity, is more famous than any non-fictional detective; though these 'non-fictional' properties are not, in general, just derived from the content of the fictions in which such objects appear.

If a fiction features an object, then it looks as if the creationist is committed to the existence of a corresponding fictional object, at least in the clear cases. According to the fiction, Holmes smokes a pipe. If the creationist is right, Holmes's pipe, the fictional entity, exists in virtue of the being featured in the appropriate fiction. The creationist is committed to a close link between facts about the fiction and what abstract entities there are. The entities that exist according to the fiction can be literally counted; the Sherlock Holmes stories feature Holmes (one), Watson (two), 
Moriarty (three)... and so on. We should be able to formulate a bridge principle that will capture the relationship that, according to the creationist, holds between what objects exist according to the fiction and which fictional objects genuinely exist. A natural first pass at stating the bridge principle for the creationist might go like this:

If there are exactly $n$ objects according to a fiction, there exist exactly $n$ fictional entities in virtue of that fiction.

This first pass can't be quite right. Concrete objects may appear in fiction. London features in the Sherlock Holmes stories but the creationist is not necessarily committed to the existence of a corresponding fictional city. London, the concrete object itself, may feature in the fiction. Fictional objects may appear in more than one fiction. Holmes, for instance, appears in both the 'A Study in Scarlet' and 'The Man with the Twisted Lip'. The creationist is not, in these cases, necessarily committed to the existence of two fictional entities, Holmes-from-A-Study-in-Scarlet and Holmesfrom-The-Man-with-the-Twisted-Lip. This may simply be a case of one fictional entity appearing in two fictions. The creationist will want to draw a distinction between 'native' and 'immigrant' objects in a fiction: an 'immigrant' fictional object is one which came into existence due to a previously told fiction, or comes from the real world, while a 'native' fictional object, for a given fiction, is one which first appears in that fiction. This terminology is from Parsons (1980, 51-52). Further theories of natives and immigrants can of course be given, but this should be enough for our purposes. 
We also want to capture what is distinctive about creationism: that there are not fictional objects unless there is a fiction to support them (along with the view that fictions themselves are created, contingent entities). So we should capture the idea that appearing in fiction is the only way for purely fictional entities to be in existence.

This suggests an amendment to the bridge principle to capture these restrictions.

There exist exactly $n$ fictional entities which are 'native' to a given fiction if, and only if, according to that fiction, there are exactly $n$ objects that are neither real non-fictional objects nor originally from another fiction.

To clarify: this should not be read as suggesting that the fiction itself must represent non-natives to be real or from other fictions. It is a nice question how to say that the $n$ objects are not real or from another fiction. One might try saying 'there are exactly $n$ objects that are neither in fact real non-fictional objects, nor in fact originally from another fiction', but we think that anyone who can understand what we intend by 'in fact' can see the ambiguity in the original formulation and understand it under the appropriate disambiguation.

A creationist may wish to impose other restrictions on the bridge principle, but there should be some principle like this endorsed by a creationist which takes us from claims about which entities exist according to a fiction to claims about which fictional entities in fact exist. 
An extra challenge facing the creationist here is what to say about fictions that are indeterminate with respect to how many things they represent as existing: e.g. Lewis's example of the chorus of sisters and cousins and aunts who accompany Sir Joseph Porter in H.M.S. Pinafore (Lewis 1978, 43). The most straightforward option for them is to allow that it is metaphysically indeterminate how many fictional entities exist. For those with less extravagant tastes, they may wish to restrict this principle to cases where the fiction does not leave it indeterminate how many entities of a particular sort exist. There are difficult problems here for the creationist we do not know how to solve (after all, we seem to be able to make claims about Porter's aunts just as much as about Eliza Bennett's sisters in Pride and Prejudice), but our objection to creationism will not turn on these matters of indeterminacy, so we will suppose the creationist can solve these problems either by accepting indeterminate existences or in some other way that keeps the spirit of the amended bridge principle above, and agrees with it in the special case where there is no relevant indeterminacy.

\section{Paradox}

Consider the following story:

'In one of the greatest reverses in mathematical history, Lucia's arguments were in the end conclusive. Naive set theory was true after all. Mathematicians everywhere were amazed, and while the realisation that sets included such strange entities as the set of all sets and the Russell set caused a new burst of interest in the foundations of mathematics, many mathematicians soon realised that their everyday work was substantially unchanged. Lucia herself took a while to get used to the celebrity thrust 
upon her, but eventually she seemed pleased with how it all turned out. "I thought I'd continue to work in obscurity, and that most set-theorists might not even notice my papers until after I was long gone: I'm lucky to have lived through going from being a mathematical heretic to a mathematical hero.'

The Russell set of naive set theory, if it existed, would be an inconsistent object: as the set of all non-self-membered sets it would contain itself and not contain itself. However, a fictional Russell set need not be inconsistent, and for the creationist it will not be: it will only be fictionally a self-member and fictionally a non-self-member, which is entirely consistent. (Just as Tony can be an alleged criminal and an alleged non-criminal without any contradiction.) That's not the problem. The problem comes when we ask how many fictional entities are there associated with our story.

Some were talked about explicitly - there is the fictional mathematician Lucia, the fictional Russell set, and the fictional set of all sets, at least. But plausibly there were all the other fictional naive sets. ${ }^{1}$ How many? Well, there's the rub. A result due to Cantor shows that naive set theory is inconsistent about how many sets there are: you can prove that, for whatever cardinality $n$ of naive sets there are, there must be at least $2^{n}$ naive sets, and that $2^{n}$ must be greater than $n$ for all cardinalities. (The set of all sets must contain all of its subsets as members, and there must always be strictly more subsets than members.) Since the fiction must be inconsistent about how many naive sets there are, the bridge principle above tells us that, for some $n$, there are exactly $n$

\footnotetext{
${ }^{1} \mathrm{We}$ are assuming for simplicity that all the naive sets of this fiction are native to the story. If you doubt this, because you think many of those sets literally exist (e.g. because they are also ZF sets), or because you think the naive sets are immigrants from other stories or theories, the example can be tweaked easily enough: let Lucia discover a new realm of schmets, alongside other sets and which happen to conform to the same axioms that naive sets were supposed to obey.
} 
objects that according to the fiction are naive sets, and exactly $2^{\mathrm{n}}$ such objects. Or at least the fiction must be inconsistent about this if it fills in the details in the right way: if you doubt that this is already implicitly true in the fiction presented above, add explicitly that Lucia proves that there are more naive sets than there are using Cantor's paradox. Once it is true according to the fiction that there are exactly $n$ and exactly $2^{\mathrm{n}}$ objects, the bridge principle delivers us a contradiction about what in fact exists: the number $\mathrm{n}$ of fictional entities which are naive sets according to that story has to be strictly greater than itself, since it must also equal $2^{\mathrm{n}}$. The existence of our story, plus the bridge principle, yields a contradiction: so the creationist bridge principle looks like it must be rejected.

If you are concerned that the fiction did not explicitly specify which cardinality $n$ causes the trouble, other fictions may serve as examples: take the fiction where it is discovered that there are number-like mathematical entities existing alongside the numbers with a very similar structure ('shnumbers'), except that the counterpart of 40 000 is the largest counting schnumber, but also that it is its own successor, so that it is equal to the schnumber 40001 . How many counting shnumbers are in the story? Exactly 40 000, and exactly 40001 . (And there are potentially other answers, perhaps, if it is implicitly true that the schnumber $40002=$ the schnumber 40001 in the story). Once you see the trick, no doubt you will be able to come up with stories that are inconsistent about how many things there are in a variety of ways, some hopefully of more literary interest than the examples above. As long as there is one case where a fiction is inconsistent about how many of its natives there are, the bridge principle will yield a literal contradiction about how many fictional objects there are. 
The difference between these contradictions and the un-worrying contradictions in impossible fictions is that most contradictions that are true according to stories are quarantined: if Watson's war wound is in inconsistent places according to the Sherlock Holmes stories, that only shows that the fictional war wound is fictionally inconsistently located, not that there is any literal contradiction about its properties. But the principle connecting existence in the fiction with literal existence, distinctive of creationist views, allows a certain kind of export of inconsistencies about the number of entities according to fictions: we can go from an inconsistency according to a fiction to a literal inconsistency about fictional objects. The existence of the fiction about Lucia, or the fiction about 40000 , threaten to demonstrate that creationism about fictional entities is itself inconsistent.

\section{Potential Creationist Responses}

Some creationists will deny that there are fictional objects corresponding to impossible fictions. We suspect this will not be very appealing, especially since creationism often, as a matter of fact, goes along with views that make many rather mundane fictions impossibly true. Kripke, for example, thinks that it is metaphysically impossible for there to be unicorns (1980, 24, 157-158), and Salmon follows him in this $(1998,317 \mathrm{n} 50)$. Perhaps a creationist could allow for creatures of fiction corresponding to metaphysically impossible fictions but not logically impossible fictions (such as those where naive set theory is true), but we struggle to see a non-ad-hoc justification for this restriction. Another reason to reject this response stems from the fact that some fictions are impossible in virtue of some minor slip or oversight on the part of the author. The case of Watson's war wound is one 
such example. We doubt that creationists will want to claim that stories fail to give rise to fictional objects simply in virtue of this sort of minor inconsistency.

Another approach a creationist can take is to deny that it is even true according to the above fiction that naive set theory is true. That may seem more plausible if creationists follow those who deny that any impossibility is ever true according to a fiction. Hanley (2004, 120-126) offers a way of reading a number of apparently impossible, or even inconsistent, fictions as possible after all. We think most of these readings are very implausible, though Hanley is right that empirical evidence of how people interpret the tales who are not philosophers with axes to grind would be evidence of whether his reading strategies are correct. While we note this is a way out for creationists, we suspect that most creationists will see this as having been driven into absurdity.

A third response, of course, is to embrace inconsistencies about abstract objects. Believers in true contradictions are already likely to embrace propositions with inconsistent properties, sets with inconsistent membership conditions, and perhaps other such entities (See Priest, 2006 parts 3 and 4), so accepting inconsistent collections of fictional objects to go along with some inconsistent fictions would not be a great departure in some ways. We do not have anything much to say against embracing true contradictions here: if the reader wishes, she can construe our target, not as being all creationists, but all creationists who wish to stay consistent. (We think this covers all actual creationists, as a sociological observation.) 
A fourth response to this problem is to not endorse the straightforward condition for accepting the existence of fictional entities offered above, but rather to be more restrictive about what it takes for a fiction to give rise to fictional objects. We think this response will be by far the most popular. The challenge here is to state informative conditions for a fictional object to be generated by a story, without the theory sacrificing too much naturalness of its formulation: if creationist theories degenerated into half-page conditions with lots of sub-clauses added in response to different classes of counter-example, that would suggest the theory had got on the wrong track to begin with.

The creationist also has to walk a tightrope between having principles that are too strong, or too weak. One problem with too strong principles is that they can lead to contradiction, as in the cases above. But if the principles of fictional entity generation are too weak, they will not be fit for the purposes that motivate realism about fictional entities. One important reason to be a realist about these entities is our apparent ability to straightforwardly quantify over them to state truths in critical contexts: "All the characters in the Twilight novels are less well developed than some characters in Jane Austen's novels", for example. We seem to be able to do this with all sorts of fictional entities: as well as fictional people, we can compare Luke Skywalker's lightsaber to D'Artagnan's rapier, or the trees of Middle-Earth to the trees of MegaCity One. We certainly can do this quantification over entities in stories that are not explicitly given names by those stories, and on the face of it we can do this whenever an object exists according to a story: we can talk about it, compare it to objects as represented by other stories, compare it with non-fictional objects, generalise about it 
and other fictional objects... and so on. Saving the appearances here while restricting the principle governing which fictional entities exist will be no easy task.

A tempting resource for restricting when we can infer the existence of a fictional entity from the fact that, according to a fiction, such-and-such exists would be to not take apparent quantification over the dubious fictional entities at face value. (One powerful technique for this is provided by Stuart Brock's fictionalism about fictional characters: see Brock 2002.) However, a creationist or other realist about fictional objects would have to tread very carefully when going this route, since theories that allow one to avoid some literal quantification over fictional objects can often be adopted to allow reinterpretation of all such quantification; a fictional realist who explains away apparent quantification over fictional entities in some cases has a harder task explaining why we should not explain away all such apparent quantification. Providing a revised principle about which fictional objects exist that threads its way through these needles will not be a straightforward task.

\section{Conclusion}

At this point we think we should leave further potential responses to the creationists. They can take comfort from the fact that they have a lot of company in grappling with cardinality paradoxes - many theories of abstract objects lend themselves to these hazards. But not too much comfort. Having companions in error does not absolve one from error. A problem for everyone is not a problem for no-one, despite the temptation, felt by some philosophers, to make this claim when fending off objections. The eliminativist about fictional entities, at least, does not face a 
Cantorian paradox about the number of such things, so at least when it comes to fictional entities this is not a problem for all sides. It deserves close attention from creationists and their sympathisers. $^{2}$

\author{
Australian National University \\ Canberra, ACT 0200 \\ Australia \\ Daniel.Nolan@anu.edu.au \\ Alexander.Sandgren@anu.edu.au
}

\title{
References
}

Brock, S. 2002. Fictionalism About Fictional Characters. Noûs 36.1: 1-21

Hanley, R. 2004. As Good As It Gets: Lewis on Truth in Fiction in Lewisian Themes:

The Philosophy of David K. Lewis, ed. F. Jackson, and G. Priest, 113-129. Oxford:

Oxford University Press.

Kripke, S. 1980. Naming and Necessity. Cambridge, Mass.: Harvard University Press.

Kripke, S. 2013. Reference and Existence. Oxford: Oxford University Press.

Lewis, D. 1978. Truth in Fiction. American Philosophical Quarterly 15.1: 37-46

Parsons, T. 1980. Nonexistent Objects. New Haven: Yale University Press.

Priest, G. 2006. Beyond the Limits of Thought, 2nd Edition. Oxford: Oxford

University Press.

Salmon, N. 1998. Nonexistence. Noûs 32.3: 277-319.

Thomasson, A. 1996. Fiction and intentionality. Philosophy and Phenomenological

Research 56.2: 277-298.

Thomasson, A. 1999. Fiction and Metaphysics. Cambridge: Cambridge University Press.

\footnotetext{
${ }^{2}$ We would like to thank Sara Bernstein, Ben Blumson, Rachael Briggs, Clare Due, Erick Llamas, Francesco Nappo, the ANU Metaphysics Reading Group, and an anonymous referee for helpful discussion.
} 
